\title{
Community based assessment on household management of waste and hygiene practices in Kersa Woreda, Eastern Ethiopia
}

\author{
Bizatu Mengistie ${ }^{1}$, Negga Baraki ${ }^{1}$
} \begin{abstract}
relationship of many diseases to improper waste management. Ethiopia.. collected through interview and observation. educational status of the respondents $(\mathrm{P}<0.01)$

Introduction

Almost any substance that is discarded is designated as waste, but it may also be considered as a potential resource. Virtually everything in the "waste stream" has residual value for someone or some business in the community. Waste represents valuable resources as ground cover to reduce erosion, fertilizer to nourish the crops, the source of energy etc (1). The management of waste should focus on how to find the value and redirect it back to the community. Unfortunately, our collecting and dumping process mix and crush everything together; and make separation an expensive and sometimes impossible task to properly manage wastes $(1,2)$.
\end{abstract}

Background: Improper waste management may have health and environmental hazards. Studies showed the

Objective: This study aimed to assess the status of waste management and hygiene practices in Kersa Woreda, Eastern

Methods: A cross sectional study was conducted in Kersa Demographic Surveillance and Health Research Centre (KDS-HRC) project site in April 2008. The study subjects were randomly selected 444 households. Data were

Results: The majority of the households, (66\%) disposed solid wastes in open dumps and only $6.9 \%$ of the households had temporary storage means for solid waste. About $98.4 \%$ of the respondents revealed that the responsibility of waste management is left for women and girls. Only $36.4 \%$ households had latrines and almost all were simple unsanitary traditional pits. From those households with latrine the habit of hand-washing after defecation was reported to be only about $5.1 \%$. The habit of hand washing after defecation is significantly associated with the

Conclusion: in the study community household management of waste is in poor condition. Health-workers and local authorities must pay special emphasis to improve these conditions. Further in-depth studies should also be encouraged to look for improved interventions. [Ethiop. J. Health Dev. 2010;24(2):103-109]

Improper waste management may have health, environmental and economic problems. Ecological phenomena such as water, soil, and air pollution have been attributed to improper management of solid wastes. The U.S public health service has published the result of the study tracing the relationship of 22 diseases to improper solid waste management. Waste water is the cause of enteric communicable diseases. Human excreta contains disease causing organisms, thus it is the source of many infections (3-5).

Sanitation is fundamental to human development and security. The combined effects of inadequate sanitation, unsafe water supply and poor personal hygiene are responsible for 88 percent of childhood deaths from diarrhoea. Every year, the failure to tackle these problems claims the lives of 1.5 million children and results in severe welfare losses - wasted time, reduced productivity, ill health, impaired learning, environmental degradation and lost opportunities - for millions more (6$8)$.

Improved sanitation attributes to $36 \%$ reduction in risk of diarrhoea while hand washing with soap reduces the risk of diarrhoea by $48 \%$ (9). In addition, good hygiene practices improve overall health through reduced rates of pneumonia, scabies, skin and eye infections, and influenza (10). Hand washing is also associated with lower respiratory infection (11).

Waste management is a critical issue worldwide. Open, unregulated dumps are still the predominant methods of waste disposal in most developing countries (1). Globally, 2.6 billion people or 39 percent of the world population do not use improved sanitation. Some 1.1 billion people still defecate in the open air. Ten countries, including Ethiopia are home to 81 per cent of them. Open defecation is largely a rural phenomenon, most widely practiced in Southern Asian and Sub-Saharan Africa. At current rates of progress the world will miss the MDG sanitation target by almost 1 billion people. The magnitude of the hygiene challenge also remains overwhelming $(12,13)$. 
In Sub- Saharan Africa, 69 percent of the population do not have access to improved sanitation facilities. At the current rate of progress, the sanitation MDG will not be met for a long time. Although difficult to predict using current models, some suggest it may even be as late as $2076(11,14)$.

Waste management is a growing public concern in Ethiopia (15). In many cities of the country, waste management is poor and solid wastes are dumped along roadsides and into open areas, endangering health and attracting vermin (16). Access to sanitation is also among the lowest in the world. Sixty percent of the population still practice open field defecation. Only 12 percent $(8 \%$ in the rural and $29 \%$ in the urban) of the population use improved sanitation facilities. Urban households are more than three times as likely as rural households to have access to improved toilet facilities (12). However, studies conducted by Research Inspired Policy and Practice Learning in Ethiopia and the Nile Region (RIPPLE) in the SNNPR indicate a substantial increase in the number of household latrines since the deployment of Health Extension Workers. It shows an increase in a few years, from $16 \%$ to $94 \%$ coverage in Mirab Abaya Woreda and $10 \%$ to $69 \%$ in Alaba Special Woreda. Nevertheless, these studies indicate hand washing facilities and practice to be still poor (17).

Lack of provisions to proper sanitation facilities can hinder the development of a country. This may be a challenge to achieve Millennium Development Goal. Provision of adequate sanitation facilities is not only a socioeconomic and developmental issue, but also an issue of self respect, human dignity and public health (18).

Therefore, this study was designed to assess solid waste and human excreta management in Kersa Demographic Surveillance and Health Research Center project site (KDS-HRC) to give insight about magnitude of the problem.

\section{Methods}

The study was conducted in April 2008 in 10 rural and two urban Kebeles of Kersa Demographics Surveillance and Health Research Center (KDS-HRC) project site. The project site is located in Eastern Hararghe Zone of Oromia Region in about $482 \mathrm{kms}$ east of Addis Ababa. And about $44 \mathrm{Kms}$ from Harar. The project site was selected by Haramaya University for field research center. The study area had a population of 48,192 distributed in 12 kebeles (19).

A cross sectional study design was used to assess the status of waste management. The sample size was calculated using a population proportion formula which gave a total size of 444 study households) and distributed proportionally to population size (number of households) in the kebeles. Structured questionnaire and observational check list was used to collect data. The interview questionnaire was administered in Oromiffa, the local language in the study area.

Before the commencement of the actual data collection the interviewers were trained for one day by the investigators and the instrument was pre-tested. Some amendment was made after the pre-test. Data was collected from the households through interview and observation by trained data collectors of the project site. The investigators supervised the data collection process to ensure the completeness of the questionnaire. The respondents of the interview were the household heads or spouses. Preferably the wife was given priority when both were present. The proposal was ethically approved by the Haramaya University, Health Sciences Faculty Ethical Review Committee. Informed consent of study subjects was secured orally before the initiation of the data collection.

Data entry, coding and cleaning was made prior to data analysis using EPI-info version 3.3.2. The data were analyzed by using SPSS version 16 statistical program. Statistical test for significance were carried out at $5 \%$ level of significance and 95\% confidence level.

\section{Results}

The range of responses for the different variables varied from 426 to 439 out of the total 444 households sampled for study ( $96 \%$ to $98.9 \%$ response rate). Most of the sampled households, $391(88.4 \%)$ were from rural area and the remaining, $50(11.6 \%)$ were from urban area. Two third of the respondents were females. Among the respondents the majority, $329(75.6 \%)$ were illiterate. Most of the respondents were Muslims, 419 (95\%), and $420(95.2 \%)$ were Oromo by ethnicity. Regarding occupation of heads of the households the majority, 326 $(73.9 \%)$ were farmers. In half, $215(49.8 \%)$ of the households, family size were in the range of 4-6 persons (Table 1).

From total of 439 respondents, 387 (88.2\%), reported that they clean their home and compound regularly. Regarding solid waste storage, only 30 (6.9\%) of the households had temporary storage means (a container or a place where the solid waste is temporally stored before final disposal) in their compound. Of these $10(33.3 \%)$ used dug pits and only $4(13.3 \%)$ have been observed to have cover for the stored waste. From those having temporary storage, $20(66.6 \%)$ households responded that they have separate storage for different types of wastes and $23(76.6 \%)$ dispose stored solid waste before three days. The study participants were also asked about their hand washing practice after handling of solid wastes. The majority, $379(85.9 \%)$ reported that they regularly wash their hands after they handle solid wastes. But among them only $193(50.9 \%)$ used soap or ash to wash their hands, $138(36.4 \%)$ used only water and the rest 48 $(12.7 \%)$ used other materials instead of soap or ash to wash their hands (Table 2). 
Table 1: Socio-demographic characteristics of the study subjects in

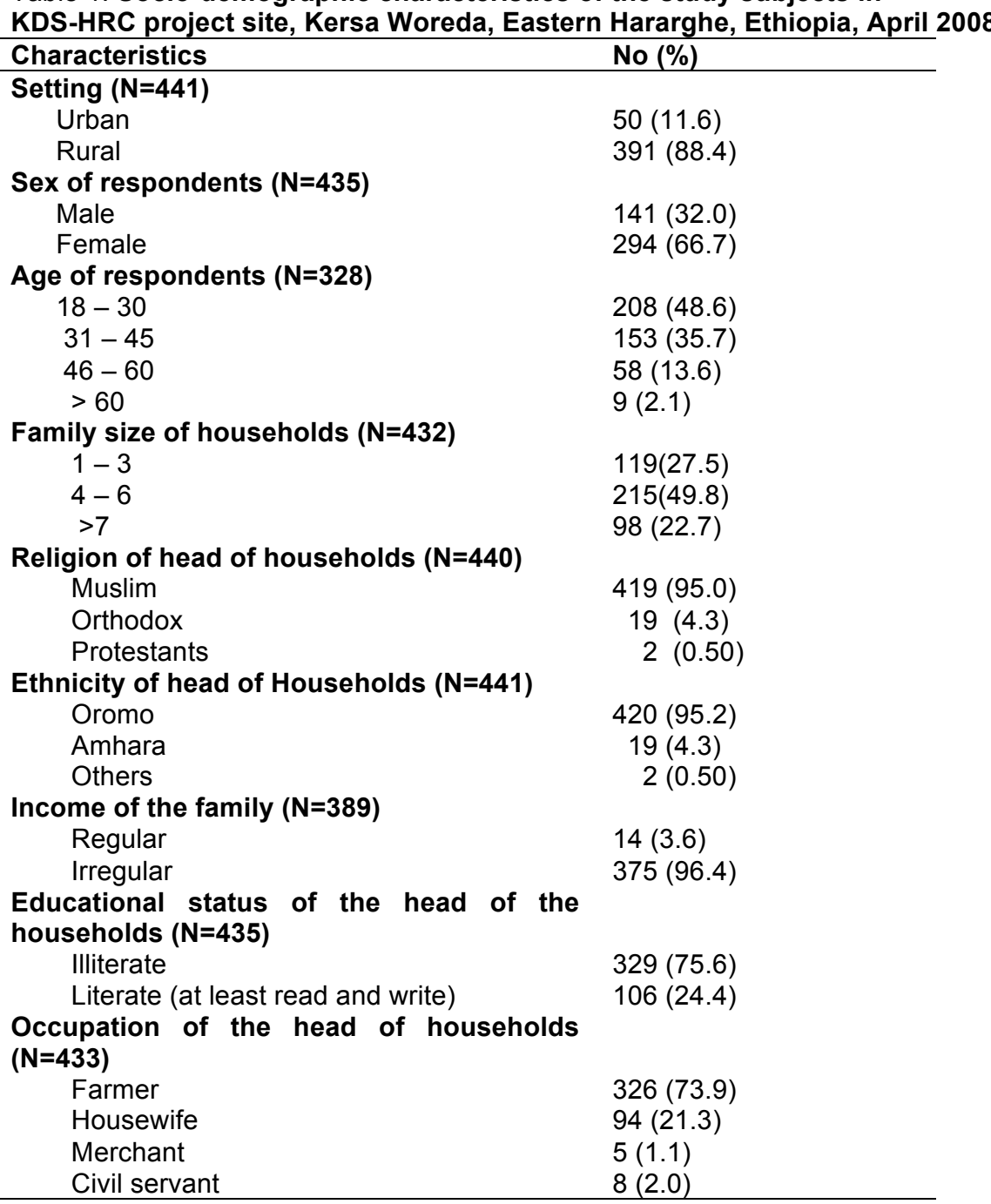

Table 2: Shows solid waste management of households in KDS-HRC project site, Kersa woreda, Eastern Hararghe, Ethiopia, April 2008.

\begin{tabular}{|c|c|c|}
\hline Variables & Frequency & Percent \\
\hline \multicolumn{3}{|c|}{ Cleaning of household compounds ( $N=439)$} \\
\hline No & 52 & 11.8 \\
\hline Yes & 387 & 88.2 \\
\hline \multicolumn{3}{|c|}{ Presence of temporary waste storage means $(\mathrm{N}=437)$} \\
\hline No & 407 & 93.1 \\
\hline Yes & 30 & 6.9 \\
\hline \multicolumn{3}{|c|}{ Cover of waste storage means $(\mathrm{N}=30)$} \\
\hline No & 26 & 86.7 \\
\hline Yes & 4 & 13.3 \\
\hline \multicolumn{3}{|c|}{ Onsite separation of wastes before storage $(\mathrm{N}=28)$} \\
\hline No & 8 & 28.6 \\
\hline Yes & 20 & 71.4 \\
\hline \multicolumn{3}{|c|}{$\begin{array}{l}\text { Washing of hands after collection /disposal of solid } \\
\text { waste }(\mathrm{N}=436)\end{array}$} \\
\hline No & 57 & 12.9 \\
\hline Yes & 379 & 85.9 \\
\hline \multicolumn{3}{|c|}{ Type of cleaning agents used to wash hands $(N=379)$} \\
\hline Water and soap or ash & 193 & 50.9 \\
\hline Water only & 138 & 36.4 \\
\hline Water and other cleaning agents & 48 & 12.7 \\
\hline
\end{tabular}




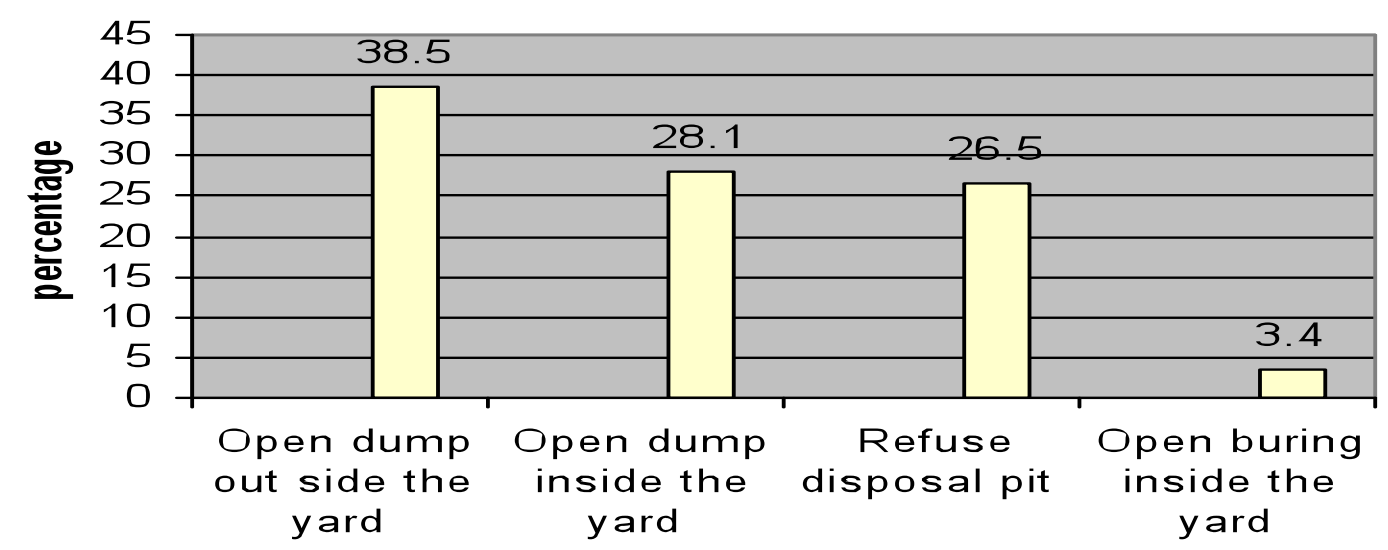

Disposal methods

Figure 1: types of solid waste disposal methods in KDS-HRC project site, Kersa woreda, Eastern Hararghe , Ethiopia, April 2008.

From a total of 439 households whose responses were obtained, $181(38.5 \%)$ explained that they disposed wastes in open dump in the yard, $132(28.1 \%)$ in open dump outside the yard and $125(26.5 \%)$ in open pits (Figure 1). However, $376(85.6 \%)$ of the households reported they use the solid waste as manure.

The study also revealed that in most of the households, $424(98.4 \%)$ waste management was the responsibility of women (girls and mothers). Men (fathers and boys) were reported to manage waste only in $7(1.6 \%)$ of the households.

From a total of 428 households assessed for presence of excreta disposal systems, only $156(36.4 \%)$ reported that they have latrine; while $272(63.6 \%)$ were without latrine. From those households who had latrine, 143 (91.7\%) were traditional pit latrines, and $136(87.2 \%)$ were owned privately. In $74(47.4 \%)$ of the households possessing latrines, feces was observed on the floor or wall of the latrines and in the compound. Presence of flies was observed in $103(67.3 \%)$ of the households. The finding of this study also revealed that 404 (93.7\%) households did not have appropriate wastewater disposal systems and; hence they simply flushed the waste water in or around their compounds (Table 3 ).

Out of the total 156 respondents who indicated the availability of latrine; only $13(8.3 \%)$ had hand washing facilities near the latrine. However, it was only $8(5.1 \%)$ of the respondents from households with latrines reported washing their hands after defecation (Figure 2). From these, five expressed to use soap and water and three reported that they use water only to wash their hands.

Table 3: Liquid waste management at household level in KDS-HRC project site, Kersa woreda, Eastern Hararghe, Ethiopia, April 2008.

\begin{tabular}{lll}
\hline Variables & Frequency & Percent \\
\hline $\begin{array}{l}\text { Presence of appropriate } \\
\text { system }\end{array}$ & wastewater disposal & \\
No & 404 & 93.7 \\
Yes & 27 & 6.3 \\
$\begin{array}{l}\text { Availability of latrine } \\
\text { Yes }\end{array}$ & 156 & 36.4 \\
No & 272 & 63.6 \\
$\begin{array}{l}\text { Type of latrine } \\
\text { Traditional pit latrine }\end{array}$ & 143 & 91.7 \\
$\quad$ VIP latrine & 13 & 8.3 \\
$\begin{array}{l}\text { Ownership of latrine } \\
\text { Private }\end{array}$ & 136 & 87.2 \\
Shared & 20 & 12.8 \\
Presence of flies in and around the latrine & 50 & 32.7 \\
No & 103 & 67.3 \\
Yes & & \\
\hline
\end{tabular}




\section{Percentage of}

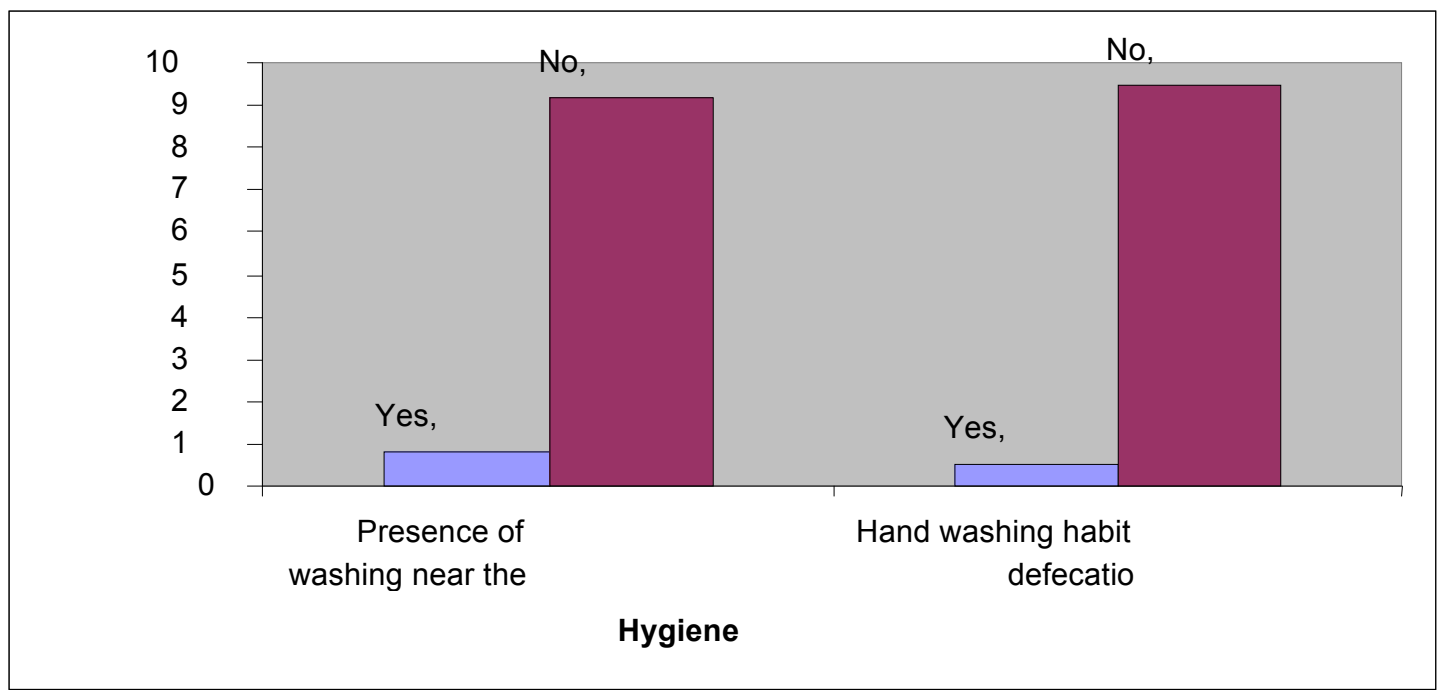

Figure 2: Hygiene practices at household level in KDS-HRC project site, Kersa woreda, Eastern Hararghe , Ethiopia, April 2008.

\section{Discussion}

Provision of adequate sanitation facilities is not only a socioeconomic and developmental issue but also an issue of self respect, human dignity and public health (18). The basic functional units of solid waste management start with onsite storage and handling of wastes. This study indicated that only $30(6.9 \%)$ had temporary storage for the generated solid waste. Moreover from those households which had temporary storage only $4(13.3 \%)$ were found to have cover at the time of data collection. This indicates that the stored wastes were exposed to insects and rodents. The vast majority of the respondents, $387(88.2 \%)$ reported that they clean their home and compound regularly. Also 379 (85.9\%) reported that they wash their hands after handling solid wastes. These two practices need to be encouraged and enhanced.

Many researchers have underlined the relationship between public health and improper solid waste management (20). This study indicated that almost all the households dispose solid wastes in open dump, open pit or by open burning. This leads to a polluted environment. This finding is similar with a survey of SNNPR, Ethiopia (2000), where majority, (67\%,) of the households dispose waste in open fields (21). This finding is not different from a similar study conducted in Haramaya Woreda in 2003, where it was reported that open disposal of refuse and feces was practiced in about $93.4 \%$ of the households (22).

Utilizing of solid waste for different purpose rather than to dump it for no use has many advantages. The present study indicated that the vast majority, $376(85.6 \%)$, of the households utilize solid waste as manure. This, however, was done without prior proper composting operations. It would be more effective if they are supported by appropriate composting techniques. This finding is higher when compared to the finding of 2000 welfare monitoring survey conducted in Ethiopia. The finding showed $45.6 \%$ of the household waste in the rural areas and $5.5 \%$ in the urban areas were utilized as manure in garden and fields (21). The onsite separation and use of waste for different benefits should be encouraged; but with the precaution of its proper treatment and handling.

Hand-washing with soap is a cost effective intervention not only against diarrheal diseases but also for the prevention of acute respiratory infections (11). Diarrhea episodes are reduced: $36 \%$ by improving sanitation and $48 \%$ through hand washing with soap (9). The majority $379(85.9 \%)$ of the respondents in the current study claimed that they wash their hands regularly after touching of solid wastes. But, it is only 193 (50.9\%) of them reported the use of soap or ash to clean their hands.

In communities where the usage of latrine is low the prevalence water borne diseases, especially diarrhea, is found to be very high $(23,24)$. The present study revealed that only $156(36.4 \%)$ of the surveyed households had access to latrine. The rest of the households did not have any fixed place for defecation. They were found to use back-yard or the bush for defecation. The finding is consistent with a study conducted in India (2007) in which $69.1 \%$ of the households had no access to toilet. However, the present finding is relatively higher when compared with Ethiopia's coverage; which is $12 \%$; according to the Joint WHO and UNICEF Global Water Supply and Sanitation Assessment 2010 Report (12).

From those households who had latrine; most, 143 (91.7\%), use traditional pit latrines which could create conducive environment for flies to breed unless proper cover is used for the hole and kept clean. In this study, 
human feces were also observed on the floor and wall of many of the latrines and inside the compound. This could cause enteric communicable diseases which affect the inhabitants and the community at large.

The presence of hand washing facilities near the latrines encourages the users to wash their hands after toilet use. However, this study showed only $13(8.3 \%)$ of the households having latrines had hand-washing facilities near the latrines. Washing of hand with soap after visiting toilet (or after defecation) has a paramount importance in decreasing of diarrheal and other parasitic diseases (9). The study revealed only $8(5.1 \%)$ of the households with latrines wash their hands after defecation. This is significantly associated with the educational status of the households $(\mathrm{P}<0.01)$. Even then, three reported that they use only water to wash their hands which is not an effective means to remove the filth and pathogenic microorganisms.

\section{Conclusion}

This study revealed that household management of waste in the community is poor. More than ninety percent of the households flush away waste water indiscriminately. Only very small proportion of the households had temporary storage for solid waste. About two third of the households did not have latrines, and almost all of the available latrines were traditional pits in poor sanitary conditions. Therefore, this study recommends the following actions in order to alleviate the problems of solid waste management and sanitation in the studied community:

- Community based education on waste management and hygiene is essential by strengthening Health Extension Workers in the area.

- Encourage the use of wastes for economic benefits such as manure through composting which is better suited to organic wastes.

- Further research is needed focusing on higher level integrated waste management option such as reuse, recycling and composting which contributes to economic development efforts.

\section{Acknowledgements}

We would like to express our deepest appreciation to the College of Health Sciences for providing us the opportunity to conduct this study. Our sincere thanks also goes to KDS-HRC Coordinating Office for unreserved guidance and financial support to undertake the study in the project site. We would also like to express our gratitude to the library staff for providing the team the reference materials.

Our last but not list acknowledgment and indebtedness goes to Ato Gudina Egeta and Ato Zinabu Anamo for their constructive comments and suggestion in developing the proposal for this study.

\section{References}

1. William PC, Mary AC, Barbara S. Waste management. Environmental Sciences: A global concern. McGraw-Hill publisher, New York. 2005; 3-44.

2. Sharama BK. Solid, toxic, and hazardous waste. Environmental chemistry. Goal publishing, India. 2005; 455-466.

3. George T, Hillary T, Samuel A. Evolution of solid waste management. Integrated solid waste management. McGraw Hill Book Corporation, New York. 1993;3-21.

4. Katzenelson E, Buium I, Shavel H. Risk of communicable disease infection associated with waste water irrigation in agricultural settlements. American Association for the Advancement of sciences. 2005;194(8): 944-46.

5. Sunder L. Environmental health. Community Medicine. CBS publisher and distributor, New Delhi. 2007; 197-228.

6. Black RE, Morris SS, Bryce J. Where and why are 10 million children dying every year. Lancet 2003; 361: 2226-34.

7. Fewtrell L, Kaufmann RB, Kay D, Enanoria W, Haller L, Colford JM. Water, sanitation, and hygiene interventions to reduce diarrhea in less developed countries: a systematic review and meta-analysis. The Lancet Infectious Diseases. 2005:5(1): 42-52.

8. UNICEF. Progress for Children: A Report Card on Water and sanitation. 2006: 5 [Cited 2010 April']; Available from: URL: http://www. Unicef.org/publications/files/Progress for_Children No._5.

9. Cairncross S, Hunt C, Boisson S, Bostoen K, Curtis V, Fung I and Schmidt WP. Water, sanitation and hygiene for the prevention of diarrhoea. International Journal of Epidemiology. 2010;39:(1): 193-205.

10. UNICEF. Water, Sanitation and Hygiene. 2009 [Cited 2010 May]; Available from: URL: http://www.unicef.org/wes/ index.html.

11. Rabie $T$ and Curtis V. Hand washing and risk of respiratory infections: a quantitative systematic review. Tropical Medicine \& International Health. 2006;11(3): 258-67.

12. Joint Monitoring Programme for Water Supply \& Sanitation (JMP). Progress on Sanitation and Drinking Water, 2010 Update. UNICEF and WHO. 2010; 6-30.

13. Hutton $G$ and Bartram J. Global cost of attaining the Millennium Development Goal for water supply and sanitation. Bulletin of the World Health Organization. 2008:86(1): 1-80.

14. United Nations Development Programme (UNDP). Beyond scarcity: power, poverty and the global water crisis. Human Development Report. New York. 2006; 25-36.

15. Abebaw D. Determinants of Solid Waste Disposal Practices in Urban Areas of Ethiopia: A HouseholdLevel Analysis. East Africa Social Science Research Review. 2008:24(1): 1-14.

Ethiop. J. Health Dev. 2010;24(2) 
16. Tewodros T, Arjan R, Fitsum H. Household waste disposal in Mekelle city, Northern Ethiopia. Waste Management. 2008:28(10): 2003-12.

17. Tefera, W. Technical Issues of Sanitation and Hygiene in Mirab Abaya and Alaba; a case study report from the Southern Nations Region (SNNPR) of Ethiopia. RIPPLE Working Paper no.2., March 2008.

18. Legesse W, Haile Mariam D, Kloos H. Water supply and sanitation. In; Berhane Y, Haile Mariam D, Kloos H (editors). Epidemiology and Ecology of health and disease in Ethiopia. Shama Books. 2006 edition; 129-146.

19. Unpublished data from census record of the Kersa Demographic Surveillance-Health Research Center, 2007.

20. World Health Organization. Combating water borne disease at the house hold level: International network to promote house hold water treatment and safe storage. Geneva, Switzerland. WHO, 1993.
21. Ministry of water resources. Sanitation and Hygiene issue paper, Addis Ababa, Ethiopia. 2003;3.

22. Fetene G and Donald R. A Sanitation Assessment of a rural Ethiopian village. Texas Journal of Rural Realth.2003;21(4):18-23.

23. Jerry A. Waste water treatment and disposal. Basic environmental technology, water supply, waste management and pollution control, $3^{\text {rd }}$ Edition, NewJersey. 2000; 227-71.

24. Wang C. Health Promotion and Disease Prevention. Journal of Community Health. 2008;3(1): 471-91. 